\title{
Applied Strategic After-Sale Service Analysis as a New Instrument to Research its Strategic Aspects
}

\author{
Sergey Krylov \\ Academic Department of Accounting, Analysis and Audit, Ural Federal University, \\ 19 Mira Street, Yekaterinburg 620002, Russian Federation
}

\begin{abstract}
The paper treats practical and theoretical aspects of the applied strategic analysis having been developed by the author utilized by an organization in the process of its strategic after-sales service aspects research, the aftersales service score, basing on the score of the same name of the balanced scorecard. The methodology of the research consists of the concept of the balanced scorecard by Kaplan R. S., and Norton D. P. and the concept of the applied strategic analysis developed by the author. The applied strategic after-sales service analysis is assumed to encompass comparative assessment, variances diagnostics and forecast of the balanced scorecard after-sales service score value within the organization strategic goals. The analysis comprises the speed of billing, payment for the goods sold, arbitrations settlement as well as analysis of due updating of the goods delivered, speed of warranty and repair excellence, and speed of poor quality goods replacement (in case of the delivery). The applied strategic after-sales service analysis commences with the comparative assessment of the outcome indicators values for the speed of billing, payment for the goods sold, arbitrations settlement and is completed with the forecast of the factoring indicators values of speed of poor quality goods replacement (in case of the delivery). The results can be applied for long-, middle- and short-term managerial decisions development in the field of the after-sales service organization activity. The methodical instruments of the applied strategic aftersales service analysis includes methods of absolute, relative and average values, comparison, grouping, graphical and table methods, correlation-regression analysis, factoring analysis, cluster analysis, as well as expert evaluation method. The conclusion is drawn that the applied strategic after-sales service analysis is a new and sufficiently effective tool to research strategic aspects of the organization after-sales service activity and to form an analytical support for the strategic after-sales service management in the present-day economic environment.
\end{abstract}

Keywords: applied strategic analysis, balanced scorecard, after-sales service, management, organization

JEL codes: L29, M19, M41

DOI: $10.7176 / \mathrm{EJBM} / 11-24-06$

Publication date: August $31^{\text {st }} 2019$

\section{Introduction}

In present-day economic environment every organization (enterprise, firm, and company) acquires a unique set of business processes ensuring value creation for its customers, developing and retaining its customer base within the target market segment as well as satisfying the requirements of its share holders in terms of high financial profitability. Meanwhile, there is a certain value chain model comprising three successive internal business processes: innovative process, operational process and after-sales service (Kaplan \& Norton, 1996a).

The after-sales service, as one of the internal business processes, entails servicing a customer after the goods and services have been sold and delivered to him. As a rule it is composed of the goods warranty and repair, goods updating, poor quality goods replacement, billing and payment both for the goods sold and customer credit sales.

The after-sales service is assumed as some kind of the feedback between the goods manufacturer and the customers enabling to obtain adequate information about advantages and disadvantages of the goods acquired and trends for their improvements. The after-sales service excellence paves the way to the company performance success portrayed by the customer satisfaction.

The due after-sales service excellence guaranteed is to exceed the customer expectations raising his positive emotions and encouraging repeat businesses with the goods manufacturer. Almost a half of the customers suspend their further business contacts with their suppliers owing to the nasty company impression gained, since the sales staff of the suppliers has lost their interest in the customers and is reluctant to keep any further relations with them.

To assess the after-sales service process such indicators as after-sales service cost, after-sales service excellence, time cycle, i.e., time period from the claim arrival to complete defect elimination, speed of billing, paid customer credit sales time, and etc.

Ensuring the high after-sales service efficiency by decreasing the related cost raising thereby their competitiveness rate is recognized as an essential goal of the continuing (core) operations and overall performance of any organization in the long run.

The goal is certain to be reached within the outcome strategic after-sales service management. In addition, an extent of the strategic decision implementation in the field of the after-sales service management is to be 
assessed as well as the causes of variances (if any) are to be found, and a further situation development is to be forecast driving a development and improvement of the appropriate analytical instrumentation.

In view of the mentioned above, the author of the paper seeks to consider his applied strategic analysis based on the balanced scorecard to be employed in the process of the analytical support development for the strategic after-sales service management.

\section{Previous Research (Present-Day State of the Problem)}

Before discussing the author's contribution into the problem research treated in the present paper we would like to cover its present-day statement in the relevant references by well-known scholars and specialists falling into two groups: those presuming balanced scorecard practical application, those avoiding it.

It should be noted, that the scientists of the first group focus, as a rule, on the balanced scorecard analysis as a whole rather than its after-sales service score isolated.

Treating the analysis in terms of BSC as a whole Kaplan R.S., \& Norton D.P. , the founders of the balanced scorecard concept, refer to the regular enterprise strategy analysis such mechanisms (instruments) as correlation analysis, scenarios and strategic initiatives analyses, reports with the examples, expert evaluation of independent specialists, and management games as well (Kaplan \& Norton, 1996a). They believe that when a company management faces with the discrepancy between the actual BSC scores values and their target ones they ought to look at the company strategy since a well-established system of interrelated BSC scores enables business strategy evaluation rather informally than statistically. As for after-sales service research Kaplan R.S., \& Norton D.P. emphasize the importance to reduce the after-sales service time-period, to raise the related cost efficiency and improve after-sales service excellence.

According to the specialists of Horvath \& Partners the analysis exercised by the BSC scores is to cover the following basic elements (Horvath \& Partners, 2004):

Evaluation of the strategic goals attainment basing on the actual BSC scores values;

Finding out the reasons of the actual BSC scores values variance from their target ones;

Determination of the variance impact arisen on the target BSC scores values;

Studying current situation in terms of the strategic events implementation;

Stipulation of the events to be likely implemented;

Finding structural enterprise divisions with significant variances from the target BSC scores values;

Determination of the arisen trends impact on the strategy implementation success;

Establishment of the analysis subject in terms of the strategy implementation state (a structural division manager proper or a team of experts).

According to M.G. Brown, the analysis is to be used for calculation and further research of the analytical BSC scores, being some kind of 'indicators' on the organization management board reporting the managers about their activity effectiveness (Brown, 2007). The analytical indicators differ from the majority organizations' balanced scorecard scores by aligning a certain BSC score (after-sales service score included) and are added from the sub-indicators reflecting a certain organization activity direction. The sub-indicators are considered as lower level indicators that are frequently various variables of different measurement units. Each sub-indicator of the analytical indicator is provided with the weighed value depending on its efficiency, reliability and probability usefulness. The system based on the analytical indicators, under M.G. Brown, enables to evaluate the organization activity effectiveness more completely compared to the system based on the separate individually measured indicators. The analytical indicators are measured by means of the 100 -scores scale, 100 scores being the top characteristics. Within the course of analysis based on the analytical indicators calculation results found are causations of their level or effectiveness trend. Emphasized is a reason having caused difficulties or lower effectiveness. Found are factors of good effectiveness and its improvements trends. The analysis outcome results in the plan of actions to be implemented for the effectiveness to be improved or retained at the level attained. Generally, it comprises specific tasks, list of individuals responsible for their fulfillment and deadlines. Obviously, such plans of actions are to be developed basing on the appropriate analytical information. As a rule, it is the manager responsible for the indicator decayed who is to develop the plan of actions.

In line with H.K. Rampersad the analysis is to evaluate what has been accomplished and what has not and to define an extent of the goals attainment (Rampersad, 2003). Depending on the extent of the goals reached and their compliance with the target ones either the balanced scorecard scores implementation process or the BSC itself can be corrected. The analysis is to facilitate the permanent BSC agreement with the changing environment creating a continued learning effect to ensure that the organization comprehends itself better. H.K. Rampersad considers the analysis undertaken at the level of the organization and its certain employees to facilitate an overall process of learning.

H.R. Friedag and W. Schmidt notice that the balanced scorecard analysis is to evaluate the scores with actual values deviating from the target ones. In the course of the analysis it is to be stated if the contingencies are present (or absent), if the employees cope with their commitments, if the plan is correct. It should be noted that 
the strategy implementation at the enterprise has to be discussed monthly (Friedag \& Schmidt, 2002).

N.G. Olve, J. Royand and V. Wetter state obviating the need for continued measurement or analysis of overall BSC scores as an ideal management control comes to a relatively unsophisticated procedure of evaluating or monitoring dynamics of the generalized index strategy implementation (Olve, Royand \& Wetter, 2000).

Having generalized the views of the researchers assuming application of balanced scorecard for an organization performance analysis mentioned above, the following items are italicized:

The aims of the analysis exercised by the balanced scorecard is to assess an organization strategy implementation success and to match continuously the balanced scorecard with the changing environment;

The analysis is to determine the actual BSC scores values variances from the target ones, to find out their causes and to specify the organization divisions exhibiting larger variances;

The optional objective of the analysis is to research the, so called, analytical (generalized) indicators of the organization performance efficiency calculated by weighted average of the particular BSC scores and evaluated by 100 -scores scale;

The results of the analysis comprises a plan of the events to raise the organization performance efficiency or to sustain it at the level reached and a permanent effect of learning to ensure that the organization's selfunderstanding.

The second group of the researchers includes numerous scholars of the economic organization (company) performance analysis emerged in the Soviet Union and further developed in a number of the post-socialist economies.

The school is represented by one of the founders, living today, A.D. Sheremet (Sheremet, 2005, 2008) as well as V.I. Barilenko (Barilenko, 2016), G.V. Savitskaya (Savitskaya, 2013), S.A. Boronenkova and M.V. Melnik (Boronenkova \& Melnik, 2016), N.P. Lyubushin (Lyubushin, 2006).

It should be noted, that the researchers mentioned do not expose any conceptual differences in their approaches. However, they neglect to analyze an organization after-sale service as integrity of processes of aftersale goods and services warranty and repair, their updating, poor quality goods replacement, billing and payment for the goods sold as well as credit sales paid. Generally it is grouped into services delivered analysis, exercised within an organization marketing activity analysis and accounts receivable analysis executed within an organization financial position. The services delivered analysis states the list of the services the organization provides, their cost and efficiency, their impact on the demand, the relationship between the services delivery activity revenues and sales income. The accounts receivable analysis implies a research of its volume, mix (longterm, short-term, normal and outstanding), structure, middle-term and its comparison with the accounts payable.

\section{Methodology of Research}

The methodology of the research, the results being presented in the paper, is based on two concepts: the balanced scorecard concept and the applied strategic analysis concept.

The balanced scorecard concept (BSC) as an analytical instrument for strategic management was developed by American scientists Robert Kaplan and David Norton at the beginning of the 90s of the XX century (1992). It evolved further in their works (Kaplan \& Norton, 1996a, 1996b, 2001, 2003, 2004, 2005, 2006, 2008; Kaplan, Norton \& Rugelsjoen, 2010), and those of other scientists studying economics (Brown, 2007; Friedag \& Schmidt, 2002; Horvath \& Partners, 2004; Maisel, 1992; Niven, 2014; Olve, Roy \& Wetter, 2000; Rampersad, 2003), and was multiply tested. Today BSC is considered to be one of the essential and sufficiently effective facilities for strategic organization management.

It should be noted, that the main reason to develop BSC was a contradiction between contingencies aimed at setting up wider competitive opportunities and immobile accounting (financial accounting) system.

The balanced scorecard as a whole is understood as an aggregate of parameters featuring an overall organization performance in present-day market economy. It reflects a balance to be brought about between short-term and long-term goals, financial and non-financial scores, basic and auxiliary parameters, as well as internal and external factors of the organization economic activity.

The scores of the balanced scorecard are specially formed depending on the individual outlook and strategic goals of any particular organization. They represent a balance between external accounting data for the owners (shareholders), and customers, and internal characteristics of the most significant business processes, innovations, learning, and growth. That is the balance between the results of the organization performance reached and future growth. The system comprises a complex of objective quantitatively evaluated data and subjective somewhat arbitrary parameters of future growth.

The main goal of the balanced scorecard is to transform a company strategy into specific tangible objectives, scores, and end up with events.

The BSC scores are selected so that the organization managers and employees focus on the factors resulting in tremendous achievements of the organization market competitiveness. The BSC should be accessible in terms of information for the employees of all levels. The 'front-line' employees are to be well aware of the financial 
consequences of their decisions and actions. Meanwhile, the top managers must be committed to the long-term financial success.

The balanced scorecard is founded on the cause and effect links, results attain factors and their interrelation with financial scores.

The balanced scorecard encompasses four basic interrelated scores: finance, a customer, internal business processes ones as well as learning and personnel development score considered through the prism of key problems, strategic goals, scores and their target values and strategic events as well.

The BSC scores enable to characterize comprehensively a performance of both commercial, government, and non-for-profit organizations, the scores being relatively few (about 25 scores in average, as a rule).

The development of the strategic applied analysis concept was caused by the need to enhance strategic management effectiveness in unhealthy conditions of the present-day market economy, to improve its information-analytical support, thereby stipulating an expediency of further evolution of theory, methodology and methods of the overall strategic organization performance aspects to the level of the financial analysis at least being a sufficiently effective research instrument of the financial aspects of the organization performance based on the financial scores.

ASA, as a strategic management function, assumes an overall research of the strategic organization performance aspects based on the balanced scorecard (Krylov, 2010, 2013a, 2013b, 2014c).

Based on the balanced scorecard, ASA, special for any particular organization, is unable to provide any standard methods. Thereby the ASA methods are special as well for any particular organization.

The goal of the applied strategic analysis implementation is to form analytical support for making strategic management decisions.

The essential ASA objectives are the following:

1. Comparative assessment of the BSC scores values assumes comparison of their actual and target figures, determination of the balanced scorecard real and target figures variance and qualitative evaluation of the variances.

2. Diagnostics of the BSC scores variances enables to find out the results attaining factors having impact on the general or outcome BSC scores and determine the variance value by means of the appropriate methods of the factoring analysis.

3. Balanced scorecard forecast of the purposeful nature implies a primordial determination and/or correction of the target BSC scores values (in case of objective circumstances) and either determination of the specific ways of their attainment or the development of the events aimed at the elimination of the variance emerged between outcome and target BSC scores values in the future.

All the objectives are interrelated as each consecutive objective follows from the previous one: the diagnostics is exercised by the results of the BSC scores comparative assessment while their forecast takes into account the diagnostics results.

Three interrelated and agreed applied strategic analysis aspects stand out:

1. Comparative assessment of the BSC scores assumes comparison of their actual and target figures, determination of the balanced scorecard real and target figures variance and qualitative evaluation of the variances.

2. Diagnostics of the BSC scores variances enables to find out the results attaining factors having impact on the general or outcome BSC indicators and determine the variance value by means of the appropriate methods of the factoring analysis.

3. Balanced scorecard forecast of the purposeful nature implies a primordial determination and/or correction of the target BSC scores values and either determination of the specific ways of their attainment or the development of the events aimed at the elimination of the variance emerged between outcome and target BSC scores values in the future.

All the objectives are interrelated as each consecutive objective follows from the previous one: the diagnostics is exercised by the results of the BSC scores comparative assessment while their forecast takes into account the diagnostics results.

Three interrelated and agreed applied strategic analysis aspects are emphasized:

1) A strategic aspect proper, within the aspect evaluated, diagnosed and forecast are final BSC scores values for the time period of the developed strategy in effect, i.e., their strategic values;

2) A tactical aspect, within the aspect evaluated, diagnosed and forecast are interim BSC scores values by the end of the year, i.e., their tactical values;

3) An operative aspect, within the aspect evaluated, diagnosed and forecast are interim BCS scores values by the end of each month, i.e., their operative values.

The results of the analysis of the on-line BSC scores values impact on their tactical values and the results of the tactical value analysis influence the strategic ones.

The basic ASA technique comprises methods of absolute, relative and average values, comparison, 
grouping, graphical and table methods, correlation and regression analysis, factoring analysis, cluster analysis, , as well as expert evaluation method.

The applied strategic analysis accomplished by deduction presumes, firstly, a research of the general BSC scores, then specific ones. The approach defines general sequence of the ASA analysis exercise according to the following leads: financial indicators analysis, customer indicators analysis, internal business-processes indicators analysis, training and personnel development indicators analysis.

Comprising specific scores, each main lead of the applied strategic analysis: financial, customer, internal business processes and training and personnel development as well is presented through the prism of its basic objectives: comparative assessment, diagnostics and forecasting. Thus the applied strategic analysis commences with the comparative assessment of the financial scores and is completed with the forecasting of the training and personnel development score value.

The basic ASA leads, mentioned, can be transformed into specific ones such as applied strategic financial analysis, applied strategic customer analysis, applied strategic internal business-processes analysis, as well as applied strategic training and personnel development analysis. The applied strategic internal business-processes analysis is composed of the applied strategic after-sales service, applied strategic operational analysis and applied strategic innovative analysis.

When describing the ASA contents as a complex category of economics in his previous works the author assumed the applied strategic innovative analysis (ASIA) to be a kind of ASA presuming overall complex research of the strategic aspects of the organization innovative activity based on the innovative BSC's score (Krylov, 2014a, 2014b); the applied strategic financial analysis (ASFA) implying overall complex research of the organization financial position by the BSC's financial score (Krylov, 2015a, 2015b, 2015c); as well as applied strategic customer analysis (ASCA) enabling to research overall strategic aspects of the organization sales performance by its BSC's customer score (Krylov, 2016a, 2016b); the applied strategic operational analysis (ASOA) allowing comprehensive research of the strategic organization operational aspects by its BSC's operational score (Krylov, 2017). In the present paper the author considers the following kind of ASA - an applied strategic after-sales service analysis.

\section{Results}

\subsection{Concept and Essence of the Applied Strategic After-Sales Service Analysis}

The applied strategic after-sales service analysis (ASASSA), a kind of the applied strategic analysis, assumes a complex, comprehensive research of the strategic organization operational activity aspects in the field of the after-sales service of the goods manufactured basing on the after-sales service score of its balanced scorecard. It can also be taken as a facilitating function of the strategic after-sales service management.

The ASASSA subject refers to the BSC's after-sales service score indicators and the factors specifying them while the object is the strategic organization after-sales service activity aspects.

The goal of the applied strategic after-sales service analysis is to form an analytical support of making strategic decisions in the field of the after-sales service management of the goods manufactured.

To attain the ASASSA goal it's most important objectives (analogous to the BSC ones) are to be reached, such as comparative assessment, diagnostics variances, and forecast of the balanced scorecard after-sales service score.

All the objectives of the applied strategic after-sales service analysis are closely interrelated since each subsequent objective follows from the previous one: the diagnostics of the after-sales service BSC score indicators variances is exercised by the results of their comparative assessment and the indicators forecast are derived from their diagnostics variances results.

Comparative assessment of the balanced scorecard after-sales service score implies a comparison of their real and target figures, finding absolute and comparative (in \%) variances, their qualitative evaluation that depends largely on their value (Table 1).

Table 1. Exemplary Qualitative Evaluation of the Variance Characteristics of the BSC's After-Sales Service Score Real and Target Figures

\begin{tabular}{|c|c|}
\hline $\begin{array}{c}\text { Real figure variances values of the BSC's after- } \\
\text { sales element from the target ones, } \%\end{array}$ & $\begin{array}{c}\text { Qualitative evaluation of the BSC's after-sales } \\
\text { element real figure from their target ones }\end{array}$ \\
\hline Up to 1 & Fairly small \\
From 1 to 5 & Essential \\
From 5 to 10 & Significant \\
From 10 to 20 & Large \\
20 and higher & Very large \\
\hline
\end{tabular}

The diagnostics of the Balanced Scorecard after-sales service score indicators variance is based on the cause and effect links combining the BSC scores, the after-sales service score included, into the balanced complex of the outcome (general) indicators and their specifying factors (results attaining factors). 
In the course of diagnosing the balanced scorecard after-sales service score indicators variances found are results attaining factors, which impact mostly the general or outcome indicators of the BSC after-sales service score, and determined is its value by the relevant factoring analysis. The conclusions are drawn by the results obtained.

It should be noted that the outcome indicators of the more specific BSC elements (innovative score, operational and personnel training and development scores) could be considered as the factors determining the factoring indicators variances of the more general after-sales service score. So, a factoring model of the BSC after-sales service score indicators, a flowchart in the generalized form is presented in Figure 1, comprises the outcome BSC after-sales service score indicators as final (the most general) ones and five levels of the defining factors:

1-st level factors: the factoring BSC after-sales service score indicator;

2-nd level factors: some outcome indicators of the BSC operational, personnel development and training scores; 3-rd level factors: some factoring indicators of the BSC operational score;

4-th level factors: some outcome indicators of the BSC innovative, personnel training and development scores; 5-th level factors: some factoring indicators of the BSC innovative, personnel training and development scores.

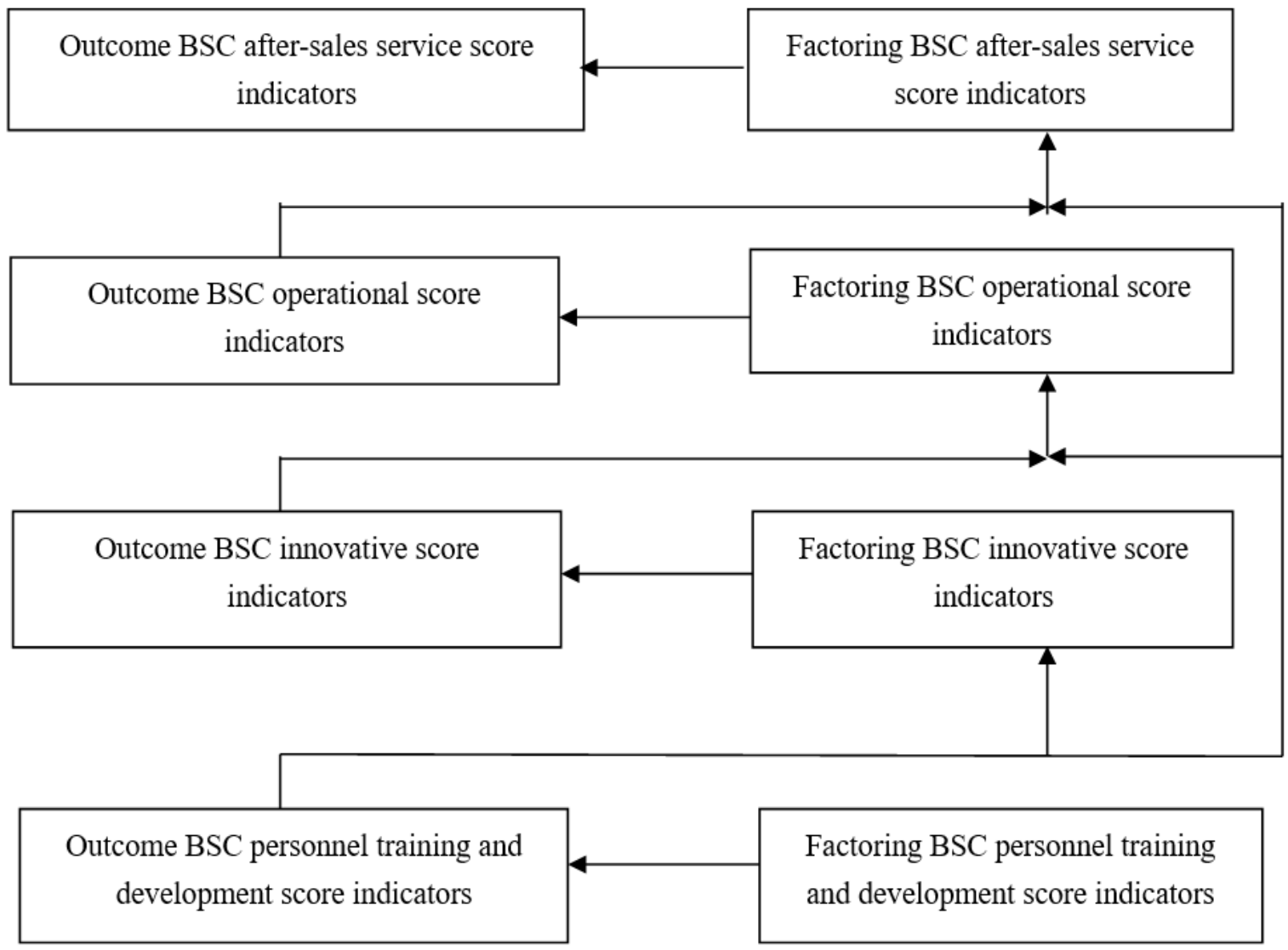

Figure 1. Flowchart of the factoring model of the BSC after-sales service score indicators in terms of its specific scores

The forecast of the BSC after-sales service score indicators values is of the purposeful nature and implies either primordial establishment or adjustment of the target BSC after-sales service score indicators values (in case of the objective conditions) and determination of the specific methods of their attainment or the development of the events aimed at the elimination of the variances emerged between the outcome and target values of the BSC after-sales service score indicators in the future. In addition, the forecast commences with the general (outcome) indicators, the factoring ones being derived from them.

The aspects of the ASASSA as a kind of ASA refer to a strategic aspect proper, as well as tactical aspect and operative aspect.

Within the scope of the strategic aspect of the applied strategic after-sales service analysis evaluated, diagnosed and forecast are final BSC after-sales service score indicators for the time-period of the developed strategy functioning, i.e., their strategic values.

Within the frame of the tactical aspect of the applied strategic after-sales service analysis evaluated, diagnosed and forecast are interim BSC after-sales service score indicators by the each year end, i.e., their tactical values. 
Within the course of the operative aspect applied strategic after-sales service analysis evaluated, diagnosed and forecast are interim BSC after-sales service score indicators by the end of each month, i.e., their operative values.

It should be noted, that all the ASASSA aspects mentioned are interrelated and agreed: the results of the operative BSC after-sales service score indicators values analysis makes an impact on their tactical values and the results of the tactical values analysis - on the strategic ones.

The applied strategic after-sales service analysis methodology instruments comprise an aggregate of techniques (ways, methods) to facilitate handling the essential problems of the analysis exercised and, respectively, its goal reached. The basic techniques of the ASASSA include methods of absolute, relative and average values, comparison, grouping, graphic and table methods, correlation-regression analysis, factoring analysis, cluster analysis, and expert evaluation methods.

\subsection{Information Base of the Applied Strategic After-Sales Service Analysis}

The information base of the applied strategic after-sales service analysis is the BSC after-sales service score formed in three steps:

4.2.1 Definition of the strategic after-sales service goals

The after-sales service managers start the formation of the BSC after-sales service score indicators from the definition of the strategic goal and after-sales service. It is based on the key problem translated from the organization strategy adopted and implies the following: which goals, in terms of the after-sales service, should be set in order to reach the goals of customer and financial targets respectively?

Obviously, should a company be set a long-term goal of reaching outstanding financial results it is to organize after-sales service process of the manufactured goods and services to be appreciated by its customers.

It should be noted, that a process of the balanced scorecard after-sales service score development clarifies the strategic after-sales service goals and defines the critical parameters of their attainment. Meanwhile, the strategic aims included into the BSC after-sales service score are special and separate for each organization within the specific conditions of time and location and cannot be replaced. They enable to translate the aftersales service score of the overall strategy, i.e., after-sales service strategy, into a set of specific target definitions referred to the balanced scorecard after-sales service score.

In addition, the strategic after-sales service goals and their indicators measurements, on the one hand, specify those of the customer and financial scores, on the other, they are a basis of the definition of the goals and measuring indicators of such BSC scores as operational, innovative, and personnel training and development scores.

When defining the strategic after-sales service goals it is worthwhile to reach substantial and sustained competitive advantages owing to the due after-sales service excellence and reduced cost.

In spite of the strategic after-sales service goals being special and separate for each organization within the specific conditions of time and location we consider, e. g., a number of strategic after-sales service goals universal in many respects for any type of organization:

Ensuring faster poor quality goods replacement (in case of the delivery);

Providing faster warranty and repair excellence;

Implementing due delivered goods updating (e.g., machinery and equipment);

Ensuring fastest billing, payment for the goods sold and arbitration.

Completing an overview of the strategic goals of the organization manufactured goods after-sales service we need to emphasize that the after-sales service is considered to be the third of the business processes and the attainment of its strategic goals facilitates further strategic customer and financial goals to be reached.

4.2.2 Construction of the strategic after-sales service map

The strategic goals of the after-sales service are not irrelevant and isolated from each other, visa versa, as it has been mentioned above; they are interrelated having a strong interactive impact. To define and record the cause and effect links between the separate strategic after-sales service goals is one of the basic tasks of the BSC aftersales service score. The cause and effect links defined reflect a strong relevance between the separate strategic after-sales service goals. In the course of the process an intuitive after-sales service managers' insight on the cause and effect links between the separate strategic goals of the after-sales service is transformed into the actual ones that are reflected (documented) in the strategic map of the after-sales service.

The strategic after-sales service map is presented as a flowchart document reflecting the cause and effect links between the separate strategic goals of the organization after-sales service. It is viewed as the flowchart, where the strategic goals of the after-sales service are presented as separate blocks and the cause and effect links between them as arrows. The strategic after-sales service map is one of the components of the strategic internal processes map and that of the overall strategic map.

As an example provided is a strategic after-sales service map reflecting an interrelation of its predefined strategic goals being largely universal for all types of the organizations (Figure 2). 


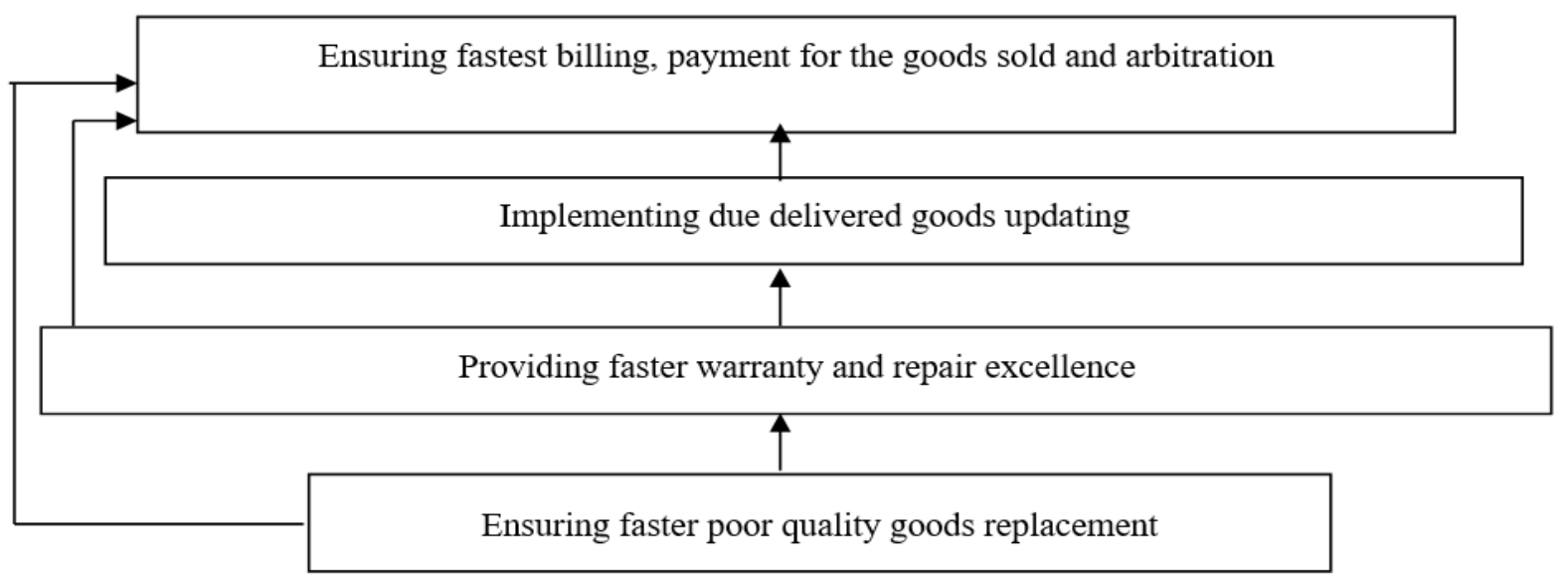

Figure 2. An example of the strategic after-sales service map

The usefulness of the strategic after-sales service maps construction to form the BSC after-sales service score is essential as they:

Reflect the interrelation and dependence between the separate strategic goals of the organization after-sales service;

Explain the reciprocal effects emerging from the strategic after-sales service goals attained;

Form the executives' awareness of the interaction and importance of the separate strategic after-sales service goals;

Facilitate a unified understanding of the organization after-sales service strategy;

Explain the value of the managerial after-sales service indicators;

Enhance deeper understanding and better links of the strategic goals of the after-sales service;

Assist in building cooperation between the heads of various organization divisions implementing after-sales service;

Create a model explaining the ways to reach a success of the organization after-sales service.

4.2.3 Selection of the after-sales service indicators

The construction of the strategic operational process map having been completed enables to select indicators of the BSC after-sales service score. The after-sales service indicators are needed to express precisely and unambiguously the content of its strategic goals and the level of their attainment. Measuring strategic goals of the after-sales service facilitates the development of the object managed in the selected operational direction. To ensure the unified understanding of the predefined strategic after-sales service goals to be reached each of them is to comprise as many as two (rarely - three and/or four exclusively) indicators.

The consideration of a larger number of the preliminary after-sales service indicators enables to understand at an early stage which indicators the BSC after-sales service score has to encompass. To employ certain aftersales service indicators within an operations management system their description (in terms of definition, formulae and parameters) is to be available. The existing after-sales service indicators would have to be assessed in terms of their usefulness (e.g., data sources, indicators measurement frequency, target values availability, etc.) As for unavailable after-sales service indicators, an accounting procedure of their values is to be worked out in advance.

Consider, as an example, certain general after-sales service indicators measuring their strategic goals mentioned above (ensuring faster poor quality goods replacement (in case of the delivery); providing faster warranty and repair excellence; implementing due delivered goods improvement; ensuring fastest billing, payment for the goods sold and arbitration) and bring them together into Table 2 .

Table 2. Certain General Indicators of the BSC After-Sales Service Score

\begin{tabular}{|l|l|}
\hline \multicolumn{1}{|c|}{ Strategic after-sale service goal } & \multicolumn{1}{c|}{ Measuring indicators } \\
\hline $\begin{array}{l}\text { Ensuring faster poor quality goods replacement (in } \\
\text { case of the delivery) }\end{array}$ & Time-period of the poor quality goods replacement. \\
\hline Providing faster warranty and repair excellence & $\begin{array}{l}\text { Life cycle. } \\
\text { A share of the first call claims to the number of the } \\
\text { repeat calls. }\end{array}$ \\
\hline Implementing due delivered goods updating & $\begin{array}{l}\text { Time-period of the earlier delivered goods } \\
\text { improvements. } \\
\text { Cost of the earlier delivered goods improvements. }\end{array}$ \\
\hline $\begin{array}{l}\text { Ensuring fastest billing, payment for the goods sold } \\
\text { and arbitration }\end{array}$ & $\begin{array}{l}\text { Speed of billing. } \\
\text { Time-period of the accounts receivables payment. }\end{array}$ \\
\hline
\end{tabular}




\subsubsection{Definition of target after-sales service indicator values}

As soon as the selection of the BSC after-sales service indicators has been completed their target values are to be defined. It should be noted that when the target value of every after-sales service indicator is stated one and another of its strategic goals are considered to be completely described. The target values of the after-sales service indicators must be rigorous but totally achievable.

The target values of the after-sales service indicators in terms of methods are determined by means of the preliminary development further disputed and agreed at the meetings and combined with a building of the business-plan model.

Nevertheless, the following principle has to be followed: a balance of the strategic after-sales service goals is to be reflected by the balance of the target values describing them.

4.2.5 Development of strategic after-sales service events

Having completed the BCS after-sales service score the relevant strategic after-sales service events may be developed. The strategic after-sales service events are assumed as the events relevant to the strategic after-sales service goals determined for the balanced scorecard after-sales service score. The strategic after-sales service events enable to specify the strategic after-sales service goals and link the after-sales service strategy with the after-sales service managers' objectives. Thereby the key idea of the BSC after-sales service score is realized, i.e., the translation of the after-sales service strategy into the specific after-sales service management actions since the BSC after-sales service score commences its performance as soon as the strategic after-sales service events are implemented.

As regards the strategic after-sales service events such events may encounter as bringing new technologies to the warranty and repair; improving the delivered goods updating process or other events irrelevant to the aftersales service activity demanding substantial resources.

Thus the strategic after-sales service events result in the basis for the resources allocation within the aftersales service strategy accomplishment. In other words, a definition of the strategic after-sales service events implies a comparison of the anticipated strategic operational goals with the available resources and technical feasibilities. Thereby the organization is being tested for the strategic after-sales service goals feasibility. The work may entail a revision of the strategic after-sales service goals defined before the development of the strategic after-sales service events.

As a rule, neither organization owns sufficient resources and capacities to implement all the strategic aftersales service events considered, resulting in setting up priorities. In this case a compliance of the after-sales service events with the strategic system of the after-sales service goals enables to assess their contribution in the implementation of the after-sales service strategy developed. The work facilitates to reach a consensus concerning the sequence of the strategic after-sales service events exercise in terms of the resources and capacities available, i.e. which are to be firstly accomplished and which ones should be postponed.

It should be noted, that the strategic after-sales service budgets are drawn up basing on the developed strategic after-sales service events. Thereby the strategic after-sales service planning is linked with the operational planning (first and foremost with budgeting).

The developed BSC after-sales service score is presented by a table comprising key issue of the BSC aftersales service score, strategic goals of the after-sales service process, their indicators, their target values and strategic after-sales service events (Table 3).

Table 3. BSC After-Sales Service Score of Organization Development

\begin{tabular}{|c|c|c|c|c|}
\hline Key issue of the BSC after-sales $\begin{array}{c}\text { strategic goals of the } \\
\text { service score }\end{array}$ & $\begin{array}{c}\text { Strafter-sales } \\
\text { after-sales service } \\
\text { score }\end{array}$ & $\begin{array}{c}\text { After } \\
\text { service score } \\
\text { indicator }\end{array}$ & $\begin{array}{c}\text { Target } \\
\text { values }\end{array}$ & $\begin{array}{c}\text { Strategic after- } \\
\text { sales service } \\
\text { event }\end{array}$ \\
\hline $\begin{array}{c}\text { What goals concerning after-sales } \\
\text { service are to be set to attain the } \\
\text { following customer and financial } \\
\text { goals, respectively? }\end{array}$ & & & & \\
\cline { 2 - 5 } & & & & \\
\cline { 2 - 5 } & & & & \\
\cline { 2 - 5 } & & & & \\
\hline
\end{tabular}

4.3 Components and sequence of the applied strategic after-sales service analysis execution

The applied strategic after-sales service analysis as a kind of the applied strategic analysis is carried out in compliance with the principle of deduction encompassing research, firstly, general indicators of the balanced scorecard operational element then specific ones.

The basic components of the ASASSA are the following:

1. Analysis of speed of billing, payment for the goods sold and arbitrations settlement;

2. Analysis of due delivered goods updating;

3. Analysis of speed of warranty and repair excellence;

4. Analysis of speed of poor quality goods replacement (in case of the delivery). 
The overall sequence of the applied strategic after-sales service analysis is built on the principle of the analysis mentioned above and its basic elements are specified as a flowchart (Figure 3).

Analysis of speed of billing, payment for the goods sold and arbitrations settlement

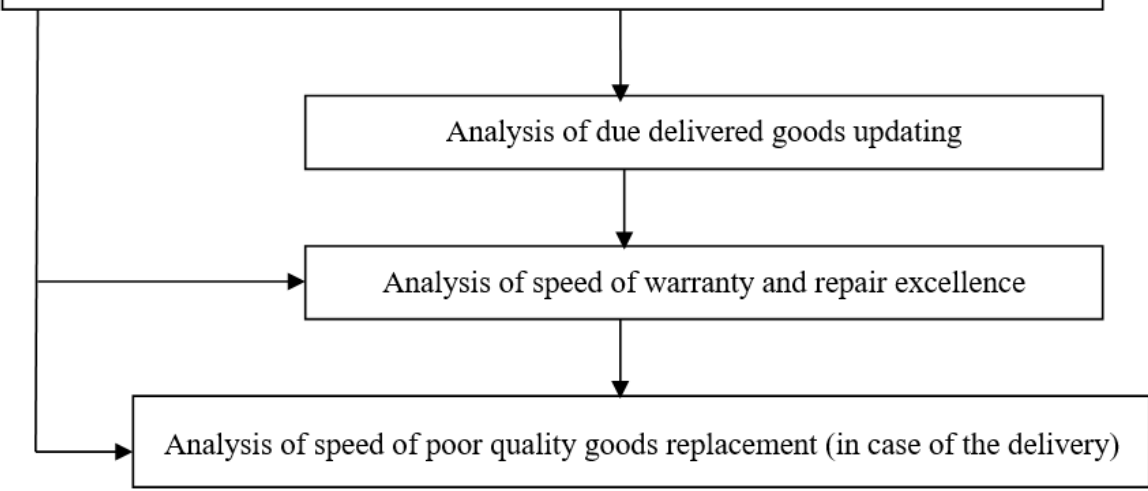

Figure 3. Sequence of the applied strategic after-sales service analysis execution

According to Figure 3 the sequence of the applied strategic after-sales service analysis execution procedure is rigorous and commences with the analysis of the speed of billing, payment for the goods sold and arbitrations settlement. Then it is followed by the analysis of the due delivered goods updating. It is furthered by the analysis of the speed of the warranty and repair excellence. The procedure is finalized with the analysis of the speed of poor quality goods replacement (in case of the delivery).

A detailed process of the applied strategic after-sales service analysis execution can be presented through the prism of its main objectives, i.e., comparative assessment, diagnostics of the variance and forecast of the BSC after-sales service score (Figure 4).

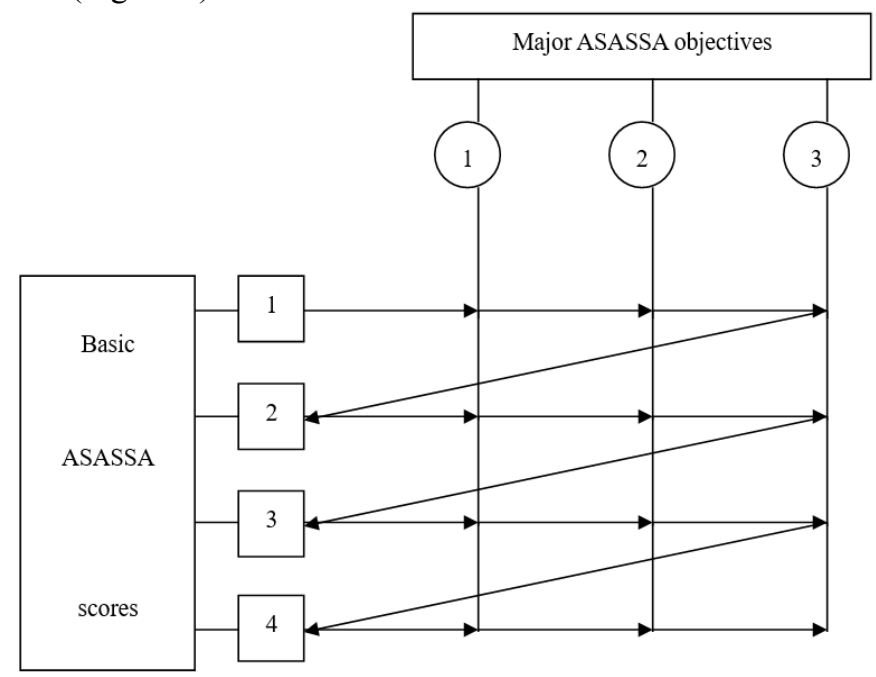

Figure 4. Flowchart of the applied strategic after-sales service analysis execution

The Figure 4 shows that considering the after-sales service score indicators to be grouped into the outcome and factoring ones the applied strategic after-sales service analysis starts from the comparative assessment of the outcome indicators characterizing the speed of billing, payment for the goods sold and arbitrations settlement and is completed with the forecast of the factoring indicators of the speed of poor quality goods replacement (in case of the delivery).

In addition, assuming the "intersection points" of the analyzed BSC after-sales service score indicators and the major objectives of the applied strategic after-sales service analysis, defined as some kind of the ASASSA scores, we are able to build a matrix (Table 4).

Denoting elements of the matrix as $p c_{i j}(i=1,2,3,4 ; j=1,2,3)$, enables to describe mathematically the ASASSA contents by means of the formulae:

$$
P C=\sum_{i=1}^{4} \sum_{j=1}^{3} p c_{i j}
$$

where $P C$ is an amount of the ASASSA scores;

$i$ is an index of the ASASSA scores: 1 is the analysis of the speed of billing, payment for the goods sold and 
arbitrations settlement, 2 is the analysis of the due delivered goods updating, 3 is the analysis of the speed of warranty and repair excellence, 4 is the analysis of the speed of poor quality goods replacement (if delivered);

$j$ is an index of the major ASASSA objectives: 1 is the comparative assessment of the BSC after-sales service score indicator values, 2 is diagnostics of the BSC after-sales service score indicator values variances, 3 is the forecast of the BSC after-sales service score indicator values.

Table 4. Matrix of the ASASSA Scores

\begin{tabular}{|c|c|c|c|}
\hline \multirow[b]{2}{*}{$\begin{array}{c}\text { Basic ASASSA } \\
\text { scores (i) }\end{array}$} & \multicolumn{3}{|c|}{ Major ASASSA objectives (j) } \\
\hline & $\begin{array}{c}\text { Comparative assessment of } \\
\text { the BSC after-sales service } \\
\text { score indicator values } \\
\text { (1) }\end{array}$ & $\begin{array}{c}\text { Diagnostics of the BSC } \\
\text { after-sales service score } \\
\text { indicator values variances } \\
(2)\end{array}$ & $\begin{array}{c}\text { Forecast of the BSC } \\
\text { after-sales service score } \\
\text { indicator values } \\
(3)\end{array}$ \\
\hline $\begin{array}{l}\text { Analysis of speed of } \\
\text { billing, payment for } \\
\text { the goods sold and } \\
\text { arbitrations settlement } \\
\text { (1) }\end{array}$ & $\begin{array}{l}\text { Comparative assessment of } \\
\text { the values of the speed of } \\
\text { billing, payment for the } \\
\text { goods sold and arbitrations } \\
\text { settlement indicator. }\end{array}$ & $\begin{array}{l}\text { Diagnostics of the speed } \\
\text { of billing, payment for the } \\
\text { goods sold and } \\
\text { arbitrations settlement } \\
\text { indicator } \\
\text { variances. }\end{array}$ & $\begin{array}{l}\text { Forecast of the speed of } \\
\text { billing, payment for the } \\
\text { goods sold and } \\
\text { arbitrations settlement } \\
\text { indicator values. }\end{array}$ \\
\hline $\begin{array}{lrr}\begin{array}{l}\text { Analysis of } \\
\text { delivered }\end{array} & \begin{array}{r}\text { due } \\
\text { goods }\end{array} \\
\text { updating (2) } & & \end{array}$ & $\begin{array}{l}\text { Comparative assessment of } \\
\text { the values of the due } \\
\text { delivered goods updating } \\
\text { indicator. }\end{array}$ & $\begin{array}{l}\text { Diagnostics of the due } \\
\text { delivered goods updating } \\
\text { indicator } \\
\text { variances. }\end{array}$ & $\begin{array}{lr}\begin{array}{l}\text { Forecast of } \\
\text { delivered }\end{array} & \begin{array}{r}\text { due } \\
\text { goods }\end{array} \\
\text { updating } & \text { indicator } \\
\text { values. } & \end{array}$ \\
\hline $\begin{array}{l}\text { Analysis of speed of } \\
\text { warranty and repair } \\
\text { excellence (3) }\end{array}$ & $\begin{array}{l}\text { Comparative assessment of } \\
\text { the values of the speed of } \\
\text { warranty and repair } \\
\text { excellence indicator. }\end{array}$ & $\begin{array}{l}\text { Diagnostics of the speed } \\
\text { of warranty and repair } \\
\text { excellence indicator } \\
\text { values variances. }\end{array}$ & $\begin{array}{l}\text { Forecast of the speed of } \\
\text { warranty and repair } \\
\text { excellence indicator } \\
\text { values. }\end{array}$ \\
\hline $\begin{array}{l}\text { Analysis of speed of } \\
\text { poor quality goods } \\
\text { replacement } \\
\text { delivered) (4) }\end{array}$ & $\begin{array}{l}\text { Comparative assessment of } \\
\text { the values of the speed of } \\
\text { poor quality goods } \\
\text { replacement (if delivered) } \\
\text { indicator. }\end{array}$ & $\begin{array}{l}\text { Diagnostics of the speed } \\
\text { of poor quality goods } \\
\text { replacement (if delivered) } \\
\text { indicator } \\
\text { variances. }\end{array}$ & $\begin{array}{l}\text { Forecast of the speed of } \\
\text { poor quality goods } \\
\text { replacement } \\
\text { delivered) indicator } \\
\text { values. }\end{array}$ \\
\hline
\end{tabular}

The matrix (Table 4) and the formulae (1) are considered as the matrix and mathematical model of ASASSA, respectively, visualizing their composition and economic contents.

The examples of the outcome and factoring indicators analyzed per every complex score of the strategic after-sales service analysis are presented in Table 5.

Table 5. Examples of Analyzed Outcome and Factoring Indicators per Each ASASSA Score

\begin{tabular}{|c|c|c|}
\hline \multirow[t]{2}{*}{ Basic ASASSA score } & \multicolumn{2}{|c|}{ Indicators analyzed } \\
\hline & Outcome & Factoring \\
\hline $\begin{array}{l}\text { 1. Analysis of speed of } \\
\text { billing, payment for the } \\
\text { goods sold and arbitrations } \\
\text { settlement }\end{array}$ & $\begin{array}{l}\text { Average speed of billing. } \\
\text { Average time-period of payment } \\
\text { for the goods sold. } \\
\text { Average time-period of } \\
\text { arbitrations settlement. }\end{array}$ & $\begin{array}{l}\text { Speed of billing to certain customers. } \\
\text { Time-period of payment for the goods } \\
\text { sold by certain customers. } \\
\text { Time-period of arbitrations settlement } \\
\text { with certain customers. }\end{array}$ \\
\hline $\begin{array}{l}\text { 2. Analysis of due delivered } \\
\text { goods updating }\end{array}$ & $\begin{array}{l}\text { Average time-period of delivered } \\
\text { goods updating. }\end{array}$ & $\begin{array}{l}\text { Time-period of goods updating } \\
\text { delivered to certain customers. } \\
\text { Cost for delivered goods updating. }\end{array}$ \\
\hline $\begin{array}{l}\text { 3. Analysis of speed of } \\
\text { warranty and repair } \\
\text { excellence }\end{array}$ & $\begin{array}{l}\text { Absolute and comparative of time } \\
\text { cycle changes. } \\
\text { A share of repeat claims for repair } \\
\text { and warranty within overall } \\
\text { claims. } \\
\text { A share of repeat claims for } \\
\text { warranty satisfied at the first } \\
\text { notice within overall claims. }\end{array}$ & $\begin{array}{l}\text { Time-period of time cycle. } \\
\text { Overall claims for repair and warranty. } \\
\text { A number of repeat claims for repair and } \\
\text { warranty. } \\
\text { A number of repeat claims for warranty } \\
\text { satisfied at the first notice. }\end{array}$ \\
\hline \begin{tabular}{|l} 
4. \\
$\begin{array}{l}\text { Analysis of speed of poor } \\
\text { quality goods replacement } \\
\text { (in case of the delivery). }\end{array}$ \\
\end{tabular} & $\begin{array}{l}\text { Average time-period of poor } \\
\text { quality goods replacement. }\end{array}$ & $\begin{array}{l}\text { Time-period of poor quality goods } \\
\text { replacement. }\end{array}$ \\
\hline
\end{tabular}




\section{Discussion}

The author believes the results of the research, undertaken to develop the applied strategic analysis concept as the research instrument of the strategic organization after-sales service activity aspects, based on the balanced scorecard after-sales service score, to carry no analogy and to be considered as new and unique one.

Let us compare the results of the author's research obtained with those of the well-known scientists and specialists in the field discussed above in the section "Previous Research (Present-day state of the problem). Some of them consider the BSC analysis application as a whole neglecting its after-sales service score, while others focus on the after-sales service analysis obviating the need for the BSC utilization.

Generally speaking, a careful study of the relevant references of the authors assuming the balanced scorecard application for an organization performance analysis has revealed an absence of as a clear well-defined BSC analysis exercise concept, as a whole, as that of its separate elements, an after-sales service one, as well. Presented are some general desires concerning the contents and sequence of the analysis execution.

Meanwhile, the author of the paper proposes the specific well-built conceptual approach to the execution of the applied strategic after-sales service analysis as a kind of the applied strategic analysis developed (Krylov, $2010,2013 \mathrm{a}, 2013 \mathrm{~b}, 2014 \mathrm{c}$ ) thereby raising the strategic organization after-sales service management. The paper clarifies his methodical aspects of the applied strategic after-sales service analysis (specified are its objectives, formed are recommendations to evaluate significant variances of the outcome BSC after-sales service indicator value from the target ones, presented is a graphic model of the factoring analysis of the variances arisen, described are scores, and built is ASASSA flowchart), and provides the examples of the outcome and factoring indicators of the BSC after-sales service score analyzed.

The author considers the building of the so called analytical indicators by the BSC scores to be inexpedient as a technique of their computations at the weighted average is of the subjective nature and deteriorates the analysis results accuracy rather than improves it.

Generally speaking, the author's vision and solution of the problem treated in the paper is of the more complete, detailed, well-thought and visualized character compared with those of the other researchers' mentioned above.

The discussed above after-sales service analysis, neglecting balanced scorecard application, is exercised by a somewhat complex instrument to research an aggregate of the after-sales service warranty and repair of the goods and services delivered, their updating, poor quality goods replacement, billing and payment for the goods sold and credit sales as well, is hardly the analysis at all. Meanwhile, there are two practically irrelevant and run separately fragments (analysis of services, executed within the organization marketing activity analysis, and analysis of the accounts receivable, run within the organization financial position analysis) with small corrections for the analyzed company's performance industry features, its strategic goals being evaded. Thereby the analysis of the kind is considered as low-informational to ensure the strategic after-sales service management effectiveness.

\section{Conclusions}

On stating the concept of the applied strategic after-sales service analysis (ASASSA) the following conclusions are drawn:

The applied strategic after-sales service analysis as a kind of the applied strategic analysis is a new and sufficiently effective instrument to research the strategic aspects of the organization after-sales service activity forming the analytical support for the strategic after-sales service management;

The ASASSA methodology is constituted by the concepts of the balanced scorecard and the applied strategic analysis;

The applied strategic after-sales service analysis presumes the comparative assessment, variances diagnostics and forecast of the BSC after-sales service score indicators of the organization within its strategic goals;

The ASASSA comprises the analysis of the speed of billing, payment for the goods sold and arbitrations settlement; analysis of the due delivered goods updating; analysis of the speed of warranty and repair excellence; and analysis of the speed of poor quality goods replacement (in case of the delivery);

The applied strategic after-sales service analysis commences with the comparative assessment of the outcome indicators, characterizing the speed of billing, the payment for the goods sold and arbitrations settlement and is completed by the factoring indicators forecast of the poor quality goods replacement (in case of the delivery);

The results of the ASASSA may be applied for the development and implementation decisions of the longterm, medium-term and short-term character in the field of the organization after-sales service activity.

\section{Implications for Future Research}

The conceptual base of the applied strategic after-sales service analysis, as a new instrument to research 
comprehensively the strategic aspects of the organization after-sales service activity through the balanced scorecard after-sales service score, discussed above, define some general contours of the ASASSA as new research and performance leads, providing a theoretical basis for its further development in terms of its practical application aspect.

The implications of the future applied strategic after-sales service analysis are as follows:

Detailed and specific ASASSA methodology development in terms of the indicators of separate stages and strategic after-sales service activity goals;

A development of the ASASSA techniques for individual companies in different industries;

The ASASSA extension onto the continuing operational activity indicators being a derivative of the BSC aftersales service score indicator;

A development of economic-mathematical models and computer programs enabling to apply the ASASSA for the after-sales service activity management.

\section{References}

Barilenko, V. I. (2016). Kompleksniy analiz khozyaystvennoy deyatelnosti [Integrated Analysis of Economic Activity]. Moscow: Yurait Publ.

Boronenkova, S. A., \& Melnik, M. V. (2016). Kompleksniy economicheskiy analiz v upravlenii predpiyatiyem [Integrated Economic Analysis in Enterprise Management]. Moscow: Forum, NITS Infra-M Publ.

Brown, M. G. (2007). Beyond the Balanced Scorecard. Improving Business Intelligence with Analytics. New York: Productivity Press.

Friedag, H. R., \& Schmidt, W. (2002). Balanced Scorecard: Mehr als ein Kennzahlensystem. Berlin: Haufe Mediengruppe.

Horvath \& Partners. (2004). Balanced Scorecard Umzetzen. Stuttgart: Schaeffer-Poeschel Verlag GmbH.

Kaplan, R. S. (2005). How the Balanced Scorecard Complements the McKinsey 7-s Model. Strategy and Leadership, 33(3), 41-46.

Kaplan, R. S., \& Norton, D. P. (1992). The Balanced Scorecard: Measures That Drive Performance. Harvard Business Review, 70(1), 71-79.

Kaplan, R. S. \& Norton, D. P. (1993). Putting the Balanced Scorecard to Work. Harvard Business Review, 71(5), 134-142.

Kaplan, R. S., \& Norton, D. P. (1996a). The Balanced Scorecard: Translating Strategy into Action. Boston: Harvard Business School Press.

Kaplan, R. S., \& Norton, D. P. (1996b). Using the Balanced Scorecard as a Strategic Management System. Harvard Business Review, 74(1), 75-85.

Kaplan, R. S., \& Norton, D. P. (2001). The Strategy-Focused Organization: How Balanced Scorecard Companies Thrive in the New Competitive Environment. Boston: Harvard Business School Press.

Kaplan, R. S., \& Norton, D. P. (2003). Strategy Maps. Boston: Harvard Business School Press.

Kaplan, R. S., \& Norton, D. P. (2004). Measuring the Strategic Readiness of Intangible Assets. Harvard Business Review, 82(2), 52-63.

Kaplan, R. S., \& Norton, D. P. (2005). The Office of Strategy Management. Harvard Business Review, 83(10), 72-80.

Kaplan, R. S., \& Norton, D. P. (2006). Alignment. Using the Balanced Scorecard to Create Corporate Sinergies. Boston: Harvard Business School Press.

Kaplan, R. S., \& Norton, D. P. (2008). The Execution Premium: Linking Strategy to Operations for Competitive Advantage. Boston: Harvard Business School Press.

Kaplan, R. S. Norton D. P., \& Rugelsjoen B. (2010). Managing Alliances with the Balanced Scorecard. Harvard Business Review, 88(1), 114-120.

Krylov, S. I. (2010). Razvitie metodologii analiza v sbalansirovannoi sisteme pokazatelei [Development of analysis's methodology in the Balanced Scorecard]. Moscow: Finance and statistics.

Krylov, S. (2013a). Applied Strategic Analysis as a New Instrument of Balanced Scorecard Comprehensive Research of the Organization Economic Activity. Science Journal of Economics. Volume 2013. Article ID sje-148, 13 Pages, doi: 10.7237/sje/148.

Krylov, S. (2013b). Applied Strategic Analysis as Further Balanced Scorecard Concept Development. Proceedings of the $11^{\text {th }}$ Eurasia Business and Economics Society (EBES) Conference. Russian Acad. Sci. Inst. Econ. Ural Branch, Ekaterinburg, Russia, 35-42.

Krylov, S. (2014a). Applied Strategic Innovative Analysis as a Research Instrument of the Strategic Innovative Organization Activity Aspects. International Journal of Economics, Finance and Management, 3(2), 100114.

Krylov, S. (2014b). Applied Strategic Innovative Analysis: Theoretical Aspects. European Journal of Business and Social Sciences, 3(3), 113-133. 
Krylov, S. (2014c). Theoretical Aspects of Economic Balanced Scorecard Analysis. Asian Journal of Finance \& Accounting, 6(1), 90-109. [Online] Available: http://dx.doi.org/10.5296/ajfa.v6i1.4821 (October 25, 2014).

Krylov, S. (2015a). Applied Strategic Analysis Concept Development: Financial Aspect. European Journal of Accounting, Auditing and Finance Research, 3(3), 30-54.

Krylov, S. (2015b). Applied Strategic Financial Analysis within Strategic Management of Organization Finance. European Journal of Business and Management, 7(15), 1-16.

Krylov, S. (2015c). Financial Analysis in Balanced Scorecard. Journal of Global Economics, Management and Business Research, 4(1), 1-14.

Krylov, S. (2016a). Applied Customer Analysis Concept. International Business Management, 10(23), 56825694.

Krylov, S. (2016b). Customer Analysis within Balanced Scorecard. International Journal of Business and Management Review, 4(10), 35-56.

Krylov, S. (2017). Concept of the Applied Strategic Operational Analysis. European Journal of Business and Management, 9(19), 33-45.

Lyubushin, N. P. (2006). Kompleksniy economicheskiy analiz khozyaystvennoy deyatelnosti [Integrated Economic Analysis of Economic Activity]. Moscow: UNITI-DANA Publ.

Maisel, L. S. (1992). Performance Management: The Balanced Scorecard Approach. Journal of Cost Management, 6(2), 47-52.

Niven, P. R. (2014). Balanced Scorecard Evolution: A Dynamic Approach to Strategy Execution. Hoboken: John Willey \& Sons, Inc.

Olve, N.-G., Roy, J., \& Wetter, V. (2000). Performance Drivers: A Practical Guide to Using the Balanced Scorecard. Chichester: John Wiley \& Sons, Ltd.

Rampersad, H. K. (2003). Total Performance Scorecard: Redefining Management to Achieve Performance with Integrity. New York, NY: Butterworth Heinemann.

Savitskaya, G. V. (2013). Economicheskiy analiz [Economic Analysis]. Moscow: Infra-M Publ.

Sheremet, A. D. (2005). Teoriya economicheskogo analiza [Theory of Economic Analysis]. Moscow: Infra-M Publ.

Sheremet, A. D. (2008). Kompleksniy analiz khozyaystvennoy deyatelnosti [Integrated Analysis of Economic Activity]. Moscow: Infra-M Publ. 